\title{
Heavy Rainfall in Kenya and Its Predictability Using Artificial Neural Networks
}

\author{
James Akuma ${ }^{1, ~ *, ~ M w e n d w a ~ M o r e e n ~}{ }^{2, \text { * }}$ \\ ${ }^{1}$ Department of Statistics and Actuarial Sciences, Jomo Kenyatta University of Agriculture and Technology, Nairobi, Kenya \\ ${ }^{2}$ Natural Resource Management, University of Eldoret, Eldoret, Kenya
}

Email address:

jamesakuma440@gmail.com (J. Akuma),mwendwamoreen96@gmail.com (M. Moreen)

\section{To cite this article:}

James Akuma, Mwendwa Moreen. Heavy Rainfall in Kenya and Its Predictability Using Artificial Neural Networks. Advances in Wireless Communications and Networks. Vol. 6, No. 2, 2020, pp. 10-13. doi: 10.11648/j.awcn.20200602.11

Received: June 15, 2020; Accepted: June 28, 2020; Published: December 31, 2020

\begin{abstract}
Heavy rainfall occurs twice a year in the country and lately, thousands of people are always left homeless and hundreds lose life due to floods and landslides where rivers, dams, lakes and sewages overflow enhancing the spread of corona virus in slums. Agricultural products in the farms are also destroyed by floods, affecting agricultural performance to decline as it the key driver of the economy growth. Therefore we used inter-crossed model which was the combination of autoregressive moving average and artificial neural network. Zebiak cane model was also used for selection of variables that were associated to physical processes and testing the network variables. Climate networks were found to be effective tool for more qualitative El Niño Southern Oscillation prediction, by looking at a warning of the oncoming of El Niño when a predestined network attribute surpasses some critical value and also feed forward artificial neural network structures were found to be the first performing structure in terms of normalized root mean squared error at a three month head time prediction. By adding the network variable, we came up with a twelve month lead time prediction with same skill to the predictions at lower set times.
\end{abstract}

Keywords: Rainfall, Zebiak Cane, Neural Network, Climate Networks, El Nino, Inter-crossed Model

\section{Introduction}

Kenya's Drainage Basin is an area of considerable diversity in terms of its orology and weather systems because of its geographical location and tectonic history. The interaction of these two components gives rise to heavy rainfall programs which is variously defined at the moment, particularly with respect to its onset and stop and consequently its duration. The heavy rainfall regimes and their attribute expression have marked influence on water supply problems generally and on agriculture in specific.

Rainfall is one of the most significant components that determine agriculture. Though when rainfall is heavy, which sometimes referred as El Niño is deadly. It has a high degree in determining the capability of an area in terms of the crops which can be cultivated and sequence of agricultural operations. According to agriculture, rainfall is crucial because it provides soil with wetness. Rainfall and soil properties depend mostly on the proportion of rain water that will constitute soil wetness reserve, that is, the overall rainfall and its statistical distribution, rainfall strength and length, soil depth and moisture holding properties, and the equilibrium between rainfall and transpiration.

Heavy rainfall is usually seasonal. The seasonal occurrence of rainfall itself is the result of the main controls of weather and climate over Kenya. This rainfall is influenced mainly by the South-East and North-East Trade winds. In the middle part of the year, Onset of westerly winds in the middle months of the year mainly affects parts of Rift valley, Central, Eastern and Nyanza regions of Kenya with floods. The heavy seasonal rainfalls in the eastern regions are as the result of the seasonal shifts of the Inter-Tropical Convergence Zone (ITCZ) which is associated to the sun's movements.

Secondly, Topography and exposure: The effect of geography and view is mainly on the amount of rainfall received at a place. In particular, topography of the Kenyan highlands, behaves to make the ITCZ preferably spread. In East Africa, it is best known that altitude is among the topographic features that has a noticeable determinant of rainfall frequency of an area [1].

Thirdly, Latitude: This ascertains the duration of the rainy 
seasons and the timing of rainfall minimum and maximum. Lastly, Inland lakes: This establishes changes to the generalized circulation patterns. Lake Victoria in Kenya is an example of an inland lake.

The existence of these changes and their consequence on the pattern of rainfall occurrence in western Kenya is as a result of heavy rainfall in Nyanza. Significant characteristic of the rainfall climatology of an area is the accusative determination of the heavy seasonal rainfall, because of the highly changeable nature of the atmospheric processes and the alterations that may happen from place to place. Although it is hard to give accurate limits of the beginning, length and halt of the rainy seasons and El Niño southern oscillation (ENSO), an overall figure should be given because it is important from the farming community's point of view [2].

Apart from patterns of rainfall, lately in Kenya we have experienced heavy rainfall that is thought to be ENSO. Late 2019 and earlier 2020, thousands of people are always left homeless and hundreds lose life due to floods and landslides where rivers, dams and lakes overflow. Agricultural products in the farms are also destroyed by floods affecting agricultural performance to decline as it the key driver of the economy growth.

Concerning this heavy rainfall, examinations from 70 rainfall gauges stations and 17 air temperatures were analyzed for months of March to June for the long rains period of time in Kenya [3]. They used Geo- statistical method to estimate standard errors for predicting trends. Assuming that the similar ascertained trends prevail, these results can be prolonged to the coming years, providing acute modification efforts that may be needed to improve food security. Prolonging the examined 1960 to 2009 effects-out until 2025, it will be found out that large parts of Kenya will have experienced more than a $100 \mathrm{~mm}$ decline in long-period rainfall by that date [4].

The ascertained rainfall trends are considerably unlike from the results given in the latest 4th Inter-governmental Panel on Climate Change assessment [5]. Chapter eleven of the Intergovernmental Panel on Climate Change Workings on first report shows that eastern Africa will probably receive a moderate five to ten percent increment in June to August precipitation. Numerous models argue the coming lean towards a more El Niño equivalent climate, where in East Africa would be anticipated to bring about enhanced March to June rainfall in Kenya. Presently, there looks to be high observational data supporting such a shift in the country.

Nevertheless, both in the Intergovernmental Panel on Climate Change modeling and in the past record of El Niño rains in Kenya, there appears a strong warming tendency in the western Indian Ocean [6], which bring about heavy rainfall hence hot and wet seasons and increased greenhouse gases. This astronomical scale circulation change seems to be modulating the effect of natural climate alterations [4]; recent El Niño March to June seasons are tending to increase leading to landslides and flooding in the country because of above normal rainfall totals followed by La Niña which is drier in the months June to October.
Therefore, when the sea surface temperatures is higher than average in the eastern equatorial Pacific [7] is referred as El Niño Southern Oscillation (ENSO) and is induced by a large-covering ocean-atmosphere interaction between the equatorial Pacific and the worldwide atmosphere [8].

Lately, efforts have been made to better the el Niño Southern Oscillation prediction ability beyond the norm predictability boundary, for example by using machine learning [9] methods, also combined with artificial neural network techniques (ANN) [10]. ANN is an organization of connected neurons that reports after optimization, a mathematical relation from more or one input variable to the output variables. In general, one has to select how big and complex the ANN structure is. The more complex an ANN is, the more it will filter the crucial information from the attributes itself, but it will necessitate more input data and will be intense computationally.

Complicated networks change out to be an effective way to describe spatiotemporal information in climate schemes [11] and can be utilized as an attribute reduction technique. These climate networks are generally built by connecting spatiotemporal placements that are importantly related with each other accordant to some measure. Hence climate networks already look to be an effective tool for more qualitative El Niño Southern Oscillation prediction, by looking at a warning of the oncoming of El Niño when a predestined network attribute surpasses some critical value [12].

\section{Methodology}

Modern approaches in neural network (NN) modeling have contributed to the nonlinear theorization of principal component analysis and canonical correlation analysis. skilled seasonal prediction is settled on the assumption that either statistics such as continuity or multi-annual drifts or slow varied boundary forcing can be employed for producing long-range forecasting that are more exact compared to climatology. Slow varied boundary forcing includes ocean temperatures; sea ice, soil moisture, and snow cover [13].

El Niño cases typically induce droughts on the western region of the Pacific and flooding cases on the eastern region and hence create impact on climate worldwide. Approximated damages for the 1997-1998 events of El Nino were in the order of billions of dollars worldwide including Kenya [14]. Hence developing of skilled forecasts of these cases, preferably with a one year head time is crucial. This research will help policy makers to mitigate the destructive results of the related weather abnormalities. For example, farmers can be informed to employ specific types of corn in El Niña years and others during La Niño years or move to hilly places during El Niño.

\subsection{The Zebiak Cane Model}

This model is used to satisfactory predict and simulate El Nino Southern Oscillation behavior, and aid in the selection of variables that are associated to physical processes. 
Network analyses are practical to the Zebiak Cane model so that to determine network attributes which could improve the prediction, before these system variables are premeditated in observation. In the Zebiak Cane model, a shallow-water ocean constituent is conjugated to a steadily shallow water Gill atmospheric state model [15].

\subsection{Network Variables}

Here in network variables, we explain the methods used to compute an attribute of a climate network, which is timetested in the Zebiak Cane model and is then utilized in the inter-crossed model thus applying the Pearson correlation of climate variables associated to El Nino Southern Oscillation. The Pearson correlation is a simple, efficient method to specify connections between nodes. Nevertheless, other properties of climate networks could be established when using mutual selective information alternatively. Furthermore, the consequence of spatial length between nodes can be examined and corrected for [16].

Nodes in neural networks are models or observation reference grid positions $\mathrm{k}$. The links are kept in a symmetrical contiguity matrix $\mathrm{B}$, where $B_{k l}=1$ if node $\mathrm{k}$ is connected to node 1 and $B_{k l}=0$ otherwise. $B_{k l}$ Is outlined as

$$
B_{k l}=\Theta\left(\left|p_{k l}\right|-\epsilon\right)-\delta_{k l}
$$

Where $p_{k l}$ the Pearson correlation between node $\mathrm{k}$ and $\mathrm{l}$ is, $\epsilon$ is the threshold value and $\Theta$ is referred as the Heaviside function. Therefore, if the Pearson correlation surpasses the threshold $\in$, the two nodes will be connected. The $\delta_{k l}$ is the Kronecker delta function, which is enforced to prevent connectedness of nodes with themselves. By using percolation theory, neural climate networks of different clusters increases before onset of $\mathrm{El} \mathrm{Niño} \mathrm{and} \mathrm{reduces}$ afterwards [17].

\subsection{Inter-Crossed Prediction Model}

Inter crossed model was applied because of its advanced stableness and rarely produces inferior prediction [18]. The observation $w_{t}$ at time $\mathrm{t}$ is outlined as

$$
w_{t}=x_{t}+m_{t}
$$

Where $x_{t}$ is modeled by a linear process and $m_{t}$ by artificial neural networks. Let $\widetilde{x_{t}}$ be the prediction part of $x_{t}$ using ARIMA, then $w_{t}-\widetilde{x_{t}}$ is the residual with respect to the determined value. This residual will be predicted by the feed forward ANN:

$$
\widetilde{m_{t}}=f\left(y_{1}(t), \cdots, y_{m}(t)\right.
$$

Explanation of each parameter: $\mathrm{f}$ is a non-linear function of the $m$ attributes $f\left(y_{1}(t), \cdots, y_{m}(t)\right.$ and $\widetilde{m_{t}}$ the prediction of the residual $w_{t}-\widetilde{x_{t}}$ at time $t$. The ARIMA $\widetilde{x_{t}}$ depends on history and non-linear function $f$ does not. The final intercrossed model $\widetilde{w_{t}}$ is

$$
\widetilde{w_{t}}=\widetilde{x_{t}}+\widetilde{m_{t}}
$$

In this research a training set of $85 \%$ and a test set of $15 \%$ of the total time series were used.

\section{Prediction Results and Conclusion}

This part constitutes the predictions of the inter-crossed model, in comparison with observations. The skill with artificial neural network structures up to three hidden layers is analyzed. CFSv2 prediction models and inter-crossed model approach to correspondent results for different hyperparameters and when using dissimilar training and test sets in a cross-validation method. The ARIMA prediction had a considerable residual as indicated by a low normalized root mean squared error hence the inclusion of artificial neural network improved the prediction. Comparing CFSv2 ensemble and inter crossed model, inter crossed model out-performs CFSv2 ensemble. Feed forward ANN structures are found to be the first performing structure in terms of normalized root mean squared error at a three month head time prediction.

Comparing the three month head prediction of the CFSv2 ensemble with the four month head prediction of the intercrossed model, both the amplification and the lag of the inter crossed model prediction are smaller. While the head time of the inter-crossed model is one month longer and the prediction skill is better in terms of normalized root mean squared error. The prediction skill of the inter-crossed model decreases at a six month head compared to the four month head time prediction. Thereby the amplification and lag of the CFSv2 prediction increases. Although the inter-crossed model does not sustain as much from the lag, it undervalues the El Niño events. In terms of normalized root mean squared error, the inter-crossed model still acquires a better prediction skill.

By adding the network variable (the set of nodes consisting of clusters of size two) $v_{2}$, we came up with a twelve month lead time prediction with same skill to the predictions at lower set times. This prediction indicates a step towards combating the poor heavy rainfall predictability mechanism. Using artificial neural network, it has the benefit of acknowledging the early warning signaling; $v_{2}$ of as either a false or true positive. Consequently, it can be a more dependable method because of its considerable information when the signal surpasses a destined threshold.

\section{References}

[1] Nieuwolt, S. (1980). The interpolation of rainfall in the Nairobi area. East African Institute for Meteorological Training and Research, Report No. 8, Nairobi.

[2] Griffiths, J. F. (1972). Climate of Africa. World Survey of Climatology, Elsevier Publishing Co. Vol. 10, Amsterdam London - New York.

[3] Funk, C., Dettinger, M. D., Michaelsen, J. C., Verdin, J. P., Brown, M. E., Barlow, M., Hoell, A., (2008). Warming of the Indian Ocean threatens eastern and southern African food security but could be mitigated by agricultural development. Proceedings of the National Academy of Sciences, U.S. 105, p. 11, 081-11, 086, ftp://chg.geog.ucsb.edu/pub/pubs/PNAS_2008.pdf. 
[4] Williams, A. P., and Funk, Chris, (2010). A westward extension of the tropical Pacific warm pool leads to March through June drying in Kenya and Ethiopia. U.S. Geological Survey Open-File Report 2010-1199, http://pubs.usgs.gov/of/2010/1199.

[5] Christensen, J. H., Hewitson, B., Busuioc, A., Chen, X. G., Held, I., Jones, R., Kolli, R. K., Kwon, W-T., Laprise, R., Rueda, V. M., Mearns, L., Menéndez, C. G., Räisänen, J., Rinke, A., Sarr, A., Whetton-Christiansen, J. H., Hewitson A., Busuioc, A., and others, (2007). Regional climate projections, Cambridge University Press, Cambridge, U. K., p. 849-940, $\mathrm{http}: / /$ www.ipcc.ch/publications_and_data/ar4/wg1/en/ch11.ht $\mathrm{ml}$.

[6] Funk, C., Senay, G., Asfaw, A., Verdin, J., Rowland, J., Michaelsen, J., Korecha, D., Choularton, R. (2005). Recent drought tendencies in Ethiopia and equatorial-subtropical eastern Africa. U.S. Agency for International Development, Washington, ftp://chg.geog.ucsb.edu/pub/pubs/FEWSNET_2005.pdf.

[7] Philander, S. G. (1990). El Nino, La Nina, and the Southern Oscillation, International Geophysics Series, vol. 46, San Diego.

[8] Bjerknes J. (1969). Atmospheric Tele-connections from the Equatorial Pacific, Mon. Weather Rev., 97, 163-172, https://doi.org/10.1175/15200493097<0163:

ATFTEP $>2.3 . C O ; 2,1969$.

[9] Wu, A., Hsieh, W. W., and Tang, B. (2006). Neural network forecasts of the tropical Pacific sea surface temperatures, neural networks, 19, 145-154, https://doi.org/0.1016/j.neunet.2006.0.004.

[10] Feng, Q. Y. and Dijkstra, H. A. (2016). Climate Network Stability Measures of El Niño Variability, Chaos, 27, 035801, https://doi.org/10.1063/1.4971784.
[11] Fountalis, I., Bracco, A., and Dovrolis, C. (2015). ENSO in CMIP5 simulations: network connectivity from the recent past to the twenty-third century, Climate Dynamic, 45, 511-538, https://doi.org/10.1007/s00382-014-2412-1.

[12] Meng, J., Fan, J., Ashkenazy, Y., and Havlin, S. (2017). Percolation framework to describe El Niño conditions, Chaos, 27, 1-15, https://doi.org/10.1063/1.4975766.

[13] Doblas-Reyes F. J., Garcia-Serrano J., Lienert F., Biescas F. P., \& Rodrigues L. R. L. (2013). Seasonal climate predictability and forecasting. Status and prospects. WIREs Climate Change, 4, 245-268. https://doi.org/10.1002/wcc.217.

[14] Adams, R. M., Chen, C. C., McCarl, B. A., Weiher, R. F. (1999). The economic consequences of ENSO events for agriculture. Clim Res. 13: 165-72.

[15] Von der Heydt, A. S., Nnafie, A., and Dijkstra, H. A. (2011). Cold tongue/Warm pool and ENSO dynamics in the Pliocene, Clim. Past, 7, 903-915. https://doi.org/10.5194/cp-7-9032011.

[16] Berezin, Y., Gozolchiani, A., Guez, O., and Havlin, S. (2012). Stability of Climate Networks with Time, Sci. Rep.-UK, 2, 18, https://doi.org/10.1038/srep00666.

[17] Rodríguez-Méndez, V., Eguíluz, V. M., Hernández-García, E., and Ramasco, J. J. (2016). Percolation-based precursors of transitions in extended systems, Sci. Rep.-UK, 6, 29552, https://doi.org/10.1038/srep29552.

[18] Hibon, M. and Evgeniou, T. (2005). To combine or not to combine: Selecting among forecasts and their combinations, Int. J. Forecasting, 21, 15-24, https://doi.org/10.1016/j.ijforecast.2004.05.002. 